\title{
Poly-3-thienylboronic acid: a chemosensitive derivative of polythiophene
}

\author{
Yulia Efremenko ${ }^{1} \cdot$ Vladimir M. Mirsky $^{1}$ (D)
}

Received: 29 June 2020 / Revised: 13 July 2020 / Accepted: 14 July 2020 / Published online: 24 July 2020

(C) The Author(s) 2020

\begin{abstract}
Poly-3-thiopheneboronic acid was synthesized by electrochemical polymerization from 3-thienylboronic acid dissolved in the mixture of boron trifluoride diethyl etherate and acetonitrile. Cyclic voltammetry during electropolymerization shows oxidative and reductive peaks growing in each next cycle. An investigation by scanning electron microscopy displayed the polymer layer like a highly flexible film of $110 \mathrm{~nm}$ thick with grains of 60-120 nm in size. Strong negative solvatochromic effect was observed. Optical spectra of poly-3-thienylboronic acid at different potentials and $\mathrm{pH}$ were studied. Potential cycling leads to a well reversible electrochromic effect. At $\mathrm{pH} 7.4$, the increase of potential leads to the decrease in the absorption band at $480 \mathrm{~nm}$ and to the rise in the absorption band at $810 \mathrm{~nm}$ with an isosbestic point at $585 \mathrm{~nm}$. Spectroelectrochemical behavior of poly-3thienylboronic acid and polythiophene was compared. Binding of sorbitol at fixed electrode potential leads to an increase in the absorbance in the shortwave band and to the decrease in the longwave band; the effect depends on the electrode potential and $\mathrm{pH}$. Perspectives of application of poly-3-thienylboronic acid as new chemosensitive material are discussed.
\end{abstract}

Keywords Chemosensitive conducting polymers $\cdot$ Polythiophene $\cdot$ Poly-3-thienylboronic acid $\cdot$ Spectroelectrochemistry Sorbitol sensing

\section{Introduction}

Extraordinary properties of conducting polymers (CP) [1-3] resulted in wide applications in different fields of science and industry: electroluminescent and electrochromic devices [4], membranes and ion exchangers [5,6], materials for energy technologies [7, 8] chemical sensors [9] and biosensors [10], artificial muscles [11], electrocatalysis [12]. A large number of $\mathrm{CP}$ such as polyacetylene, poly(3,4-ethylenedioxythiohene) (PEDOT), polyaniline, polypyrrole, polythiophene (PTh), and their derivatives have acquired a widespread recognition due to their inherent conductivity as well as tunable electrochemical, acid-base, and optical properties. Among these CP, the

Electronic supplementary material The online version of this article (https://doi.org/10.1007/s10008-020-04767-z) contains supplementary material, which is available to authorized users.

Vladimir M. Mirsky

mirsky@b-tu.de

1 Nanobiotechnology Department, Institute of Biotechnology, Brandenburg University of Technology Cottbus - Senftenberg, Senftenberg, Germany polymers with PTh backbone belong to the most explored ones, both theoretically and experimentally $[13,14]$. This class of CP attracts close attention because of the high chemical and longtime stability, high electrical conductivity, and ease of structural modification. Numerous applications of PTh and its derivatives in chemical sensing were suggested $[15,16]$. Based on PTh nitrogen dioxide sensors with electrochemically controllable affinity allowed one to get a fast sensor recovery [17]. PTh was also used as a conductmetric indicator for redox-titration in organic media [18], thus providing electrochemical transducing in non-conducting media. However, PTh itself is not chemosensitive, and in all these works, only redox properties of this polymer were used. An application of PTh in selective chemical sensors requires incorporation of a specific receptor. There are different ways of the conjugation of receptor moieties with CP [19], while the strongest coupling between a binding event and physical properties of $\mathrm{CP}$ is achieved if the receptor is incorporated directly into or very close to the conducting path of the polymer. Also, a chemosensitive material should possess no additional moieties which can lead to any interference. But in our attempt to apply electrochemically synthesized polyphenylboronic acid for conductometric sensing of fructose (this unpublished work was performed in 2003 together with Q. 
Hao), the effects were so small that we were not able to distinguish between an effect of the target analyte and possible $\mathrm{pH}$ effect of acidic impurities: despite a strong buffer, it was impossible to exclude $\mathrm{pH}$ effect in the range of $0.01-0.001$ which would be enough to get the same effect as the analyte. In this sense, a sensor based on PTh has important advantages because of the absence of basic/acidic groups in its polymer backbone which lead to strong $\mathrm{pH}$ dependence of the physical properties of polyaniline and its derivatives. Therefore, preparation of PTh with receptors incorporated close to its conducting path is a perspective way for the development of new chemosensitive materials.

One of the most used artificial receptors is the boronic acid moiety [20,21]. Boronic acid-functionalized materials overall and boronic acid substituted polymers, in particular, have been widely implemented in chemical sensing of biological analytes containing diol moiety [22, 23], for instance, carbohydrates and $\alpha$-hydroxy acids. Boronic acid forms reversible covalent complexes with compounds containing a diol group. The reaction occurs in aqueous solutions; the boronic acid is transformed into the corresponding boronate ester. The perspective to use boronic acid as the receptor for diol containing compounds was the motivation to incorporate this group into various conducting polymers. However, only recently the polythiopheneboron derivatives, namely polythiophene substituted by boronic acid, have been prepared. To our knowledge, there is only one publication discussing the physical properties of poly-3thienylboronic acid (PThBA) [24]; the polymer was synthesized using oxidation by potassium dichromat. The electrochemical synthesis of PThBA was used in [25-27]. Chen et al. [25] applied this polymer to manufacture an electrochromic device [25]. The works [26, 27] were focused on the development of sensors for hydrogen peroxide and glucose correspondingly, but the authors either did not prove the existence of the polymer film [26] or did not described film properties [27]. The receptor properties of the boronic group of PThBA have never been exploited so far.

In this work, we report electrochemical polymerization of thienyl-3-boronic acid (Fig. 1) and optimization of this process. Electrochemical synthesis in the mixture of boron trifluoride diethyl etherate (BFEE) and acetonitrile allowed us to get a highly flexible polymer film with a thickness of

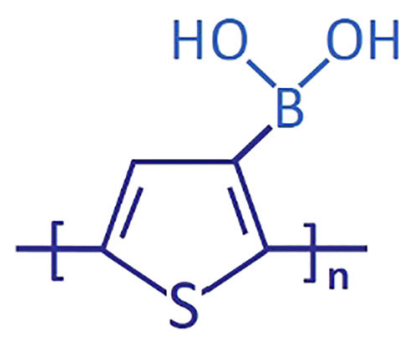

Fig. 1 Suggested structure of poly-3-thienylboronic acid
$100 \mathrm{~nm}$. We describe the structural, electrochemical, and spectroelectrochemical properties of this polymer and demonstrate its applicability for chemosensing of sugars.

\section{Experimental}

Prior to electropolymerization, 150-nm-thick gold electrodes on a glass wafer were cleaned by acetone (Chemsolute), ethanol (Merck), water, and piranha solution (a 1:3 (v/v) mixture of $30 \% \mathrm{H}_{2} \mathrm{O}_{2}$ /concentrated $\mathrm{H}_{2} \mathrm{SO}_{4}$ ). Caution: this mixture reacts violently with most organic materials and must be handled with extreme care. Then, the electrodes were rinsed thoroughly with deionized water additionally purified by the EGLA-classic system. Indium tin oxide (ITO)-coated glass slides (Sigma-Aldrich) were cleaned with ethanol and rinsed with deionized water.

Synthesis of PThBA and PTh films was performed in 50-mM solution of the corresponding monomer (SigmaAldrich) either in pure acetonitrile (Honeywell) containing $100 \mathrm{mM}$ of tetrabutylammonium hexafluorophosphate $\left(\mathrm{NBu}_{4} \mathrm{PF}_{6}\right)$ (Sigma-Aldrich) or in the mixture of $90 \%$ BFEE (Sigma-Aldrich) and $10 \%$ acetonitrile $(\mathrm{v} / \mathrm{v})$ containing $50 \mathrm{mM}$ 2,6-di-tert-butylpyridine (DTBP) (Sigma-Aldrich) by potential cycling from $-0.2 \mathrm{~V}$ to $+1.8 \mathrm{~V}$ vs. $\mathrm{Ag} / \mathrm{AgCl}$ electrode (Metrohm) filled by $2 \mathrm{M} \mathrm{LiCl}$ (Merck) in ethanol (Merck) with the same solution in the salt bridge. The proton scavenger DTBP was added to avoid a hydrogenating of BFEE during polymerization in consequence of its high sensitivity to moisture leading to side reactions. An application of the BFEE/ acetonitrile mixture for electropolymerization was optimized and exploited earlier for electropolymerization of PTh [28].

Cyclic voltammetry was performed using General Purpose Electrochemical System Autolab PGSTAT-12 with Nova 2.1.4 software. A three-electrode configuration was used. Platinum wire (ChemPur) of $0.5 \mathrm{~mm}$ in diameter served as the counter electrode in spectroelectrochemical measurements, while a planar gold electrode with an area of $\sim 1.5 \mathrm{~cm}^{2}$ was used for the same purpose in cyclic voltammetry. Measurements in buffer solution ( $\mathrm{pH}$ 7.4) consisting of $10 \mathrm{mM}$ sodium phosphate (Merck) and $140 \mathrm{mM}$ sodium chloride (Roth) were performed using $\mathrm{Ag} / \mathrm{AgCl}$ reference electrode without a salt bridge. Polymer films deposited on ITO-coated glass slides were rinsed with acetonitrile, dried nitrogen flow, and then applied for spectroelectrochemical measurements.

Scanning electron microscopy (SEM) was performed at Zeiss Microscope EVO® MA 15. Spectral and spectroelectrochemical measurements were done using spectrophotometer Evolution 200 Series from Thermo Scientific. Nikon Eclipse LV 100 microscope equipped with CCD-camera was applied for optical microscopy. The experiments were performed at room temperature. Other experimental details are described in [28]. 


\section{Results and discussion}

At the beginning of the work, we tried to make electrochemical deposition of PThBA from the solution of acetonitrile with $100 \mathrm{mM} \mathrm{NBu}_{4} \mathrm{PF}_{6}$, but the film adhesion to the electrode surface was poor, and the film growth was inhibited by relatively low conductivity of the formed material. The obtained cyclic voltammograms were similar to those reported in [27] (except the current polarity which was inverted in that work). Much better results were obtained for electrochemical polymerization of PThBA from BFEE/acetonitrile solution [29, 30]. The cyclic voltammetric curves during electropolymerization display an increase in the cathodic and anodic peaks in each next cycle (Fig. 2 ); such behavior is typical for the deposition of highly conducting materials. Both oxidation and reduction peaks were shifted symmetrically to anodic and cathodic directions correspondingly.

The morphology of films obtained from acetonitrile and BFEE/acetonitrile solution was also very different. The polymer films synthesized in acetonitrile were very heterogeneous and looked like a broken solid layer. No lateral polymer growth between gold strips on the electrode was observed (Fig. 3a). In BFEE/acetonitrile solution, the polymer growth was very fast, and a well visible lateral growth filling the gap between the strip electrodes was observed (Fig. 3b). A similar difference was observed earlier for the electropolymerization of PTh [28]. Therefore, the second electrolyte was used for electrochemical polymerization in further experiments. Being deposited at such conditions onto ITO glass slides, the polymer formed a smooth scarlet film (SI, movie 1) with a characteristic metallic shine. Already during electropolymerization, a strong electrochromic effect was observed - the color of the film was changed between scarlet and blue (SI, movie 1). The

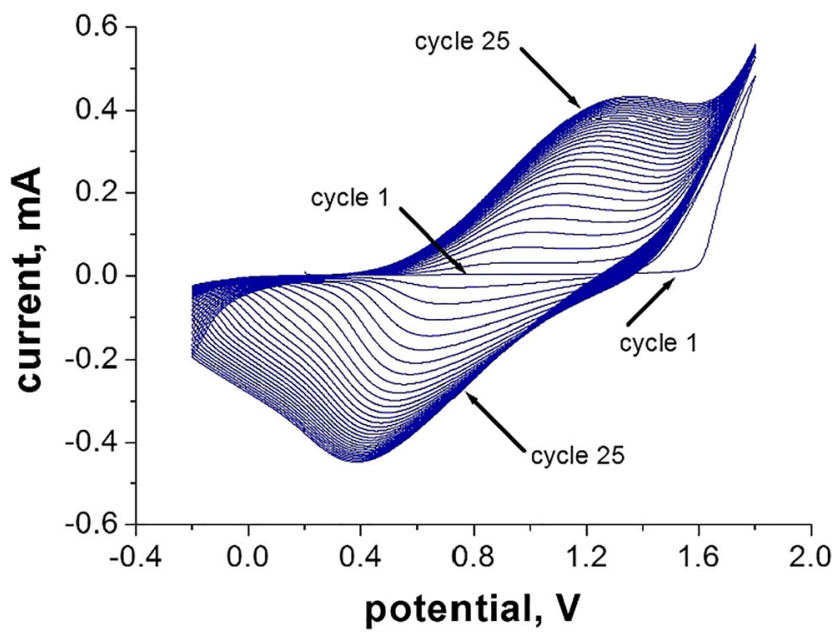

Fig. 2 Electrochemical synthesis of poly-3-thienylboronic acid by cyclic voltammetry from $50 \mathrm{mM} 3$-thienylboronic acid in the mixture of $90 \%$ boron trifluoride diethyl etherate, $10 \%$ acetonitrile $(\mathrm{v} / \mathrm{v})$, and $50 \mathrm{mM}$ DTBP. Scan rate: $100 \mathrm{mV} / \mathrm{s}$. The first 25 cycles are shown polymer film on the electrodes was stable in acetonitrile, but in aqueous solutions, the adhesion was much weaker. This can be related to the hydration of the boronic acid moiety.

Further structural investigation of PThBA films polymerized in the second electrolyte was performed using scanning electron microscopy (Fig. 4). The thickness of the film formed after 20 cycles of cyclic voltammetry was determined by SEM measurements as $110 \mathrm{~nm}$. Very close value gives a calculation based on the integration of cyclic voltammetry measured in organic electrolyte after electropolymerization (Fig. 5) and using Faraday low in the assumption that the polymer density is the same as for PTh $(1.06 \mathrm{~g} / \mathrm{mL}$ [31]). It means that almost the whole amount of the synthesized polymer is adsorbed on the electrode surface. Figure $4 \mathrm{a}$ shows the polymer film detached from the ITO. One can see high flexibility and elasticity of this film: its curvature in the field of wrinkles is comparable with the film thickness. At higher magnification, one can observe a formation of some thicker round spots, probably as a result of secondary nucleation; similar structures on the smooth polymer layer were observed for electropolymerization of N-methylaniline [32]. The film surface at higher magnification looks to be formed by densely packed grains of the size $\sim 60-140 \mathrm{~nm}$.

The electrochemical activity of PThBA in the aqueous electrolyte is very low; no clear oxidation or reduction peaks were observed in cyclic voltammograms. The same effect was described earlier for PTh [28]. In the case of PTh, the low electrochemical activity in aqueous electrolytes was explained by low penetration of hydrophilic ions from aqueous solution into the highly hydrophobic film of polythiophene [28]. This can be formally described as an increase of the oxidation potential of polythiophene in an aqueous environment but the potential value required for the polymer oxidation cannot be reached because of limited polymer stability. Due to the presence of boronic acid moieties, PThBA should be less hydrophobic than PTh, but probably this hydrophilicity still is not enough to provide a good excess for inorganic ions from aqueous solution.

The electrochemical activity of PThBA in acetonitrile is well measurable and similar to that of PTh (Fig. 5). The values of the redox potential obtained as the middle point between the peaks are $0.78 \mathrm{~V}$ for PTh and $0.82 \mathrm{~V}$ for PThBA. The values of the peak current are very similar. For both polymers, there is complete reversibility of oxidation and reduction. The gap between oxidative and reduction peaks is some higher for PThBA than for PTh; this may indicate additional hindrances for the penetration of hydrophobic ions from the electrolyte into the polymer or for the electron transfer between polymer molecules.

The polymer films of $\sim 100$-nm thickness on ITO were used for optical spectroscopy and spectroelectrochemical measurements. The spectra of PThBA in acetonitrile show a well-pronounced absorption band at 420-570 $\mathrm{nm}$ and a wide weak adsorption band around $\sim 800 \mathrm{~nm}$ (Fig. 6a) being similar 
Fig. 3 Photos of poly-3thienylboronic acid films deposited from the solutions of $50 \mathrm{mM} 3-$ thienylboronic acid in acetonitrile containing $100 \mathrm{mM} \mathrm{NBu}_{4} \mathrm{PF}_{6}$ (a) and from the mixture of $90 \%$ boron trifluoride diethyl etherate and $10 \%$ acetonitrile $(\mathrm{v} / \mathrm{v})$ containing $50 \mathrm{mM}$ DTBP (b) onto the surface of glass chip with four gold strip electrodes obtained by the light microscope

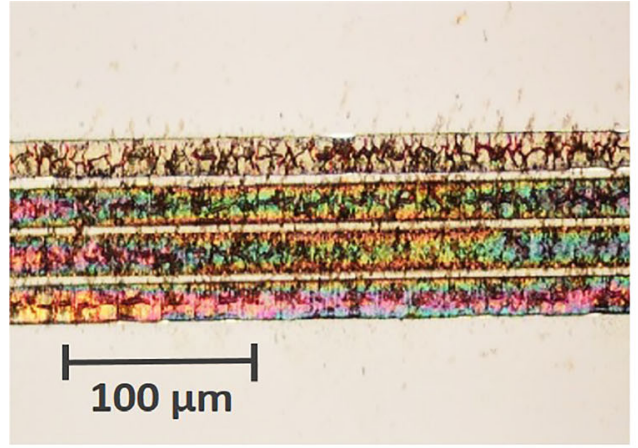

$\mathbf{a}$

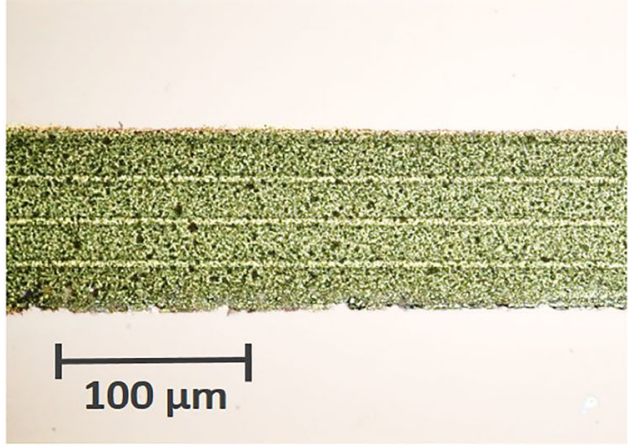

b to the spectra of PTh. Assuming that the density of PThBA is close to that of PTh, we get the value of extinction recalculated to the molar concentration of monomers $5.9 \times 10^{3} \mathrm{~L} \mathrm{~cm}^{-1}$ $\mathrm{mol}^{-1}$. In aqueous solutions, the spectra have a similar shape but with an essential shift in the wavelengths of the absorption peaks (SI Fig. S1). Incorporation of boronic acid moiety into PTh leads to the small hypsochromic shift in the main absorption band which is increasing from $\sim 5 \mathrm{~nm}$ until $\sim 20 \mathrm{~nm}$ with polymer oxidation. The spectra are qualitatively similar to those reported in [25]. Both PTh and PThBA show a strong negative solvatochromic effect, but for PTh, this effect is much larger than for PThBA. The difference in the absorption maxima in aqueous solution and in acetonitrile for PTh in the reduced state is $\sim 260 \mathrm{~nm}$, while for PThBA this effect is only $\sim 110 \mathrm{~nm}$. This may be explained by much lower energy of the ground state of PThBA in aqueous solvent due to the strong hydrophilic contribution of the boronic acid moiety (Fig. 6b).

Spectroelectrochemistry of PTh and PThBA also displays an essential difference between these polymers. Practically no influence of the electrode potential on the spectra of PTh was observed in aqueous solutions (Fig. 6b), this corresponds to the data [32]. In a contrast, an increase of the electrode potential leads to remarkable changes in the optical spectra of PThBA (Fig. 6b): the shortwave peak is decreasing while the longwave peak is increasing with an isosbestic point at $585 \mathrm{~nm}$.
Fig. 4 Scanning electron microscopy of poly-3-

thienylboronic acid films polymerized on ITO from the BFEE/ acetonitrile mixture. $\mathbf{a}, \mathbf{b}$ Detached polymer film. $\mathbf{c}$ The border of the film, one can observe also uncoated ITO surface. d Polymer film on the ITO electrode
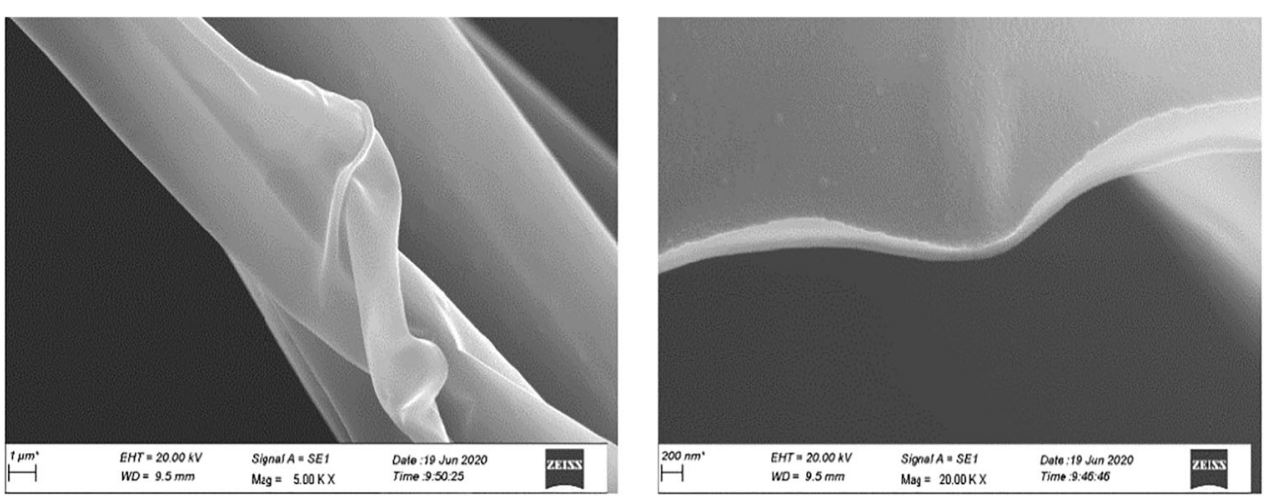

$\mathbf{a}$

b
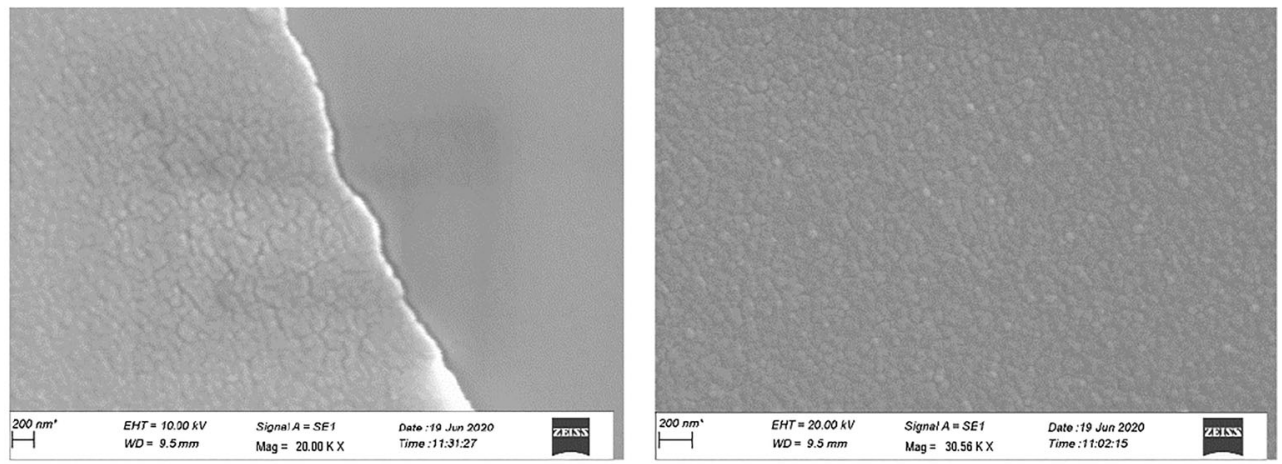

c d 


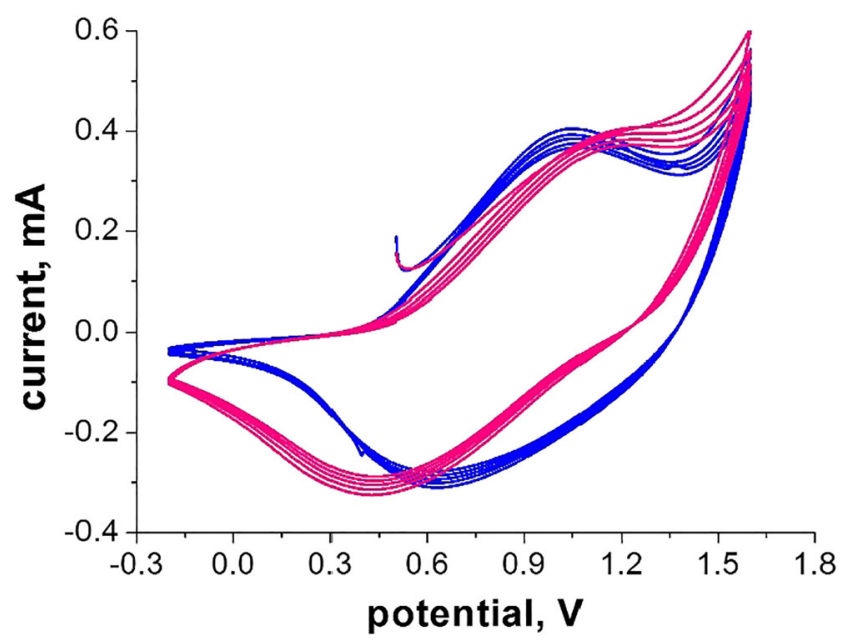

Fig. 5 Cyclic voltammetry of films of poly-3-thienylboronic acid (red) and polythiophene (blue) in acetonitrile containing $100 \mathrm{mM} \mathrm{NBu}_{4} \mathrm{PF}_{6}$. Electrode: ITO, macroscopic electrode area $1.3 \mathrm{~cm}^{2}$. Scan rate: $100 \mathrm{mV} / \mathrm{s}$

In acetonitrile, the spectroelectrochemistry of PTh and PThBA is more similar (Fig. 6a, c, d). In this case, for both polymers, an increase of the electrode potential leads to a decrease in the main adsorption band and to the increase in the adsorption in the longwave adsorption band $(600-900 \mathrm{~nm})$ with a less pronounced isosbestic point at $570-590 \mathrm{~nm}$. Both in aqueous solution and in acetonitrile the change in the transmission at $450-500 \mathrm{~nm}$ was $28-30 \%$ for the potential change between $-0.4 \mathrm{~V}$ and $1.0 \mathrm{~V}$, about the same value was obtained in the electrochromic device for the potential change for $3 \mathrm{~V}$ in acetonitrile based gel electrolyte [25].
The main feature of PThBA is the presence of a receptor group for the binding of diol moieties. Here, we demonstrate optical changes due to the binding of sorbitol (Fig. 7). With the goal to get the maximal effect of this analyte on spectral properties, the sorbitol concentration of $500 \mathrm{mM}$ was used. The binding constant of sorbitol to 3-thienylboronic acid at pH 7.4 is $\sim 300 \mathrm{~mol}^{-1}$ (SI Fig. S3). Assuming the same value for the polymerized form of this compound (PThBA), we get that at $500 \mathrm{mM}$ sorbitol concentration over $98 \%$ of the receptor moiety will be occupied. A formation of the PThBA-sorbitol conjugate leads to an increase in optical absorbance in the range $350-550 \mathrm{~nm}$ and to the decrease in the absorbance at longer wavelengths. The effect depends on the electrode potential (Fig. 7, SI Fig. S2). For the absorbance value measured near maximum $(455 \mathrm{~nm})$, the maximal value of the relative absorbance change at $\mathrm{pH} 7.4$ is reached at the electrode potential of approximately $+0.8 \mathrm{~V}$ (Fig. 7b). It is known that the binding constant of the boronic acid moiety with sugars is increasing at alkalic $\mathrm{pH}$ [33]. We have observed that $\mathrm{pH}$ increase from 7.4 to 8.0 leads to about twice a higher relative absorbance change of PThBA due to sorbitol binding (Fig. 7b). Also, in this case, the maximal effect at $\mathrm{pH} 8.0$ was observed for the oxidized state of the polymer. The magnitude of the observed effect is about the same as for polyphenylboronic acid [34] but the polymer backbone without basic/acidic groups promises a better selectivity.

Finally, the properties of PThBA are close to PTh but the presence of a chemosensitive group in PThBA makes its perspective for applications in chemical sensors. Conjugation of the receptor group with redox-active polymer allows us to consider this new material to be promising for electrochemical chemotransistors [17,
Fig. 6 Optical spectra of polythiophene (solid line) and poly-3-thienylboronic acid (dotted line) at potentials $-0.4,-0.2$. $0,+0.2,+0.4,+0.6,+0.8$, and + $1.0 \mathrm{~V}$ (potential increase is indicated by arrows) in acetonitrile containing $0.1 \mathrm{M} \mathrm{NBu}_{4} \mathrm{PF}_{6}$ and in aqueous buffer $10 \mathrm{mM}$ sodium phosphate, $140 \mathrm{mM} \mathrm{NaCl}, \mathrm{pH} 7.4$ (b) and potential influence on intensity of both adsorption bands for polythiophene (c) and poly-3thienylboronic (d) for the spectra in (a). The potentials are indicated relative quasi-reference silver electrode $(\mathbf{a}, \mathbf{c}, \mathbf{d})$ or $\mathrm{Ag} / \mathrm{AgCl}$ $(140 \mathrm{mM} \mathrm{NaCl})$ electrode (b)

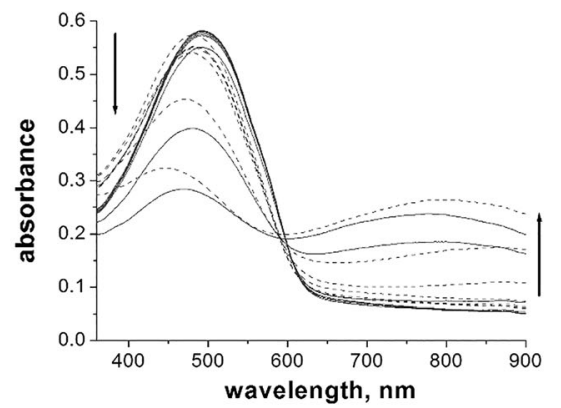

a

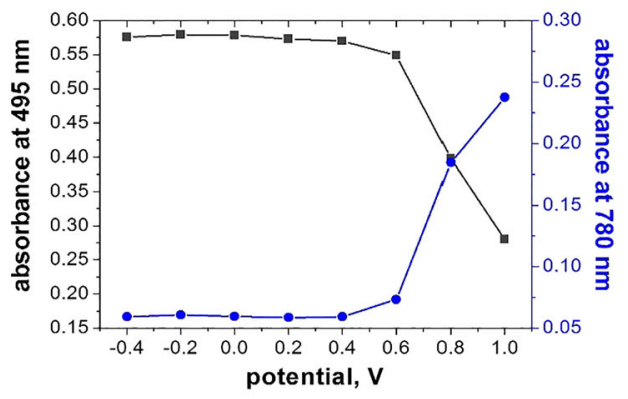

c

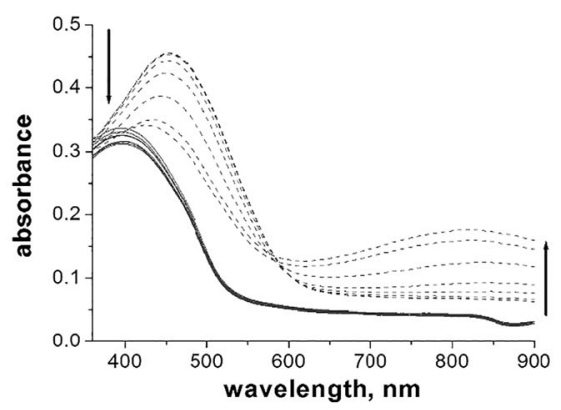

b

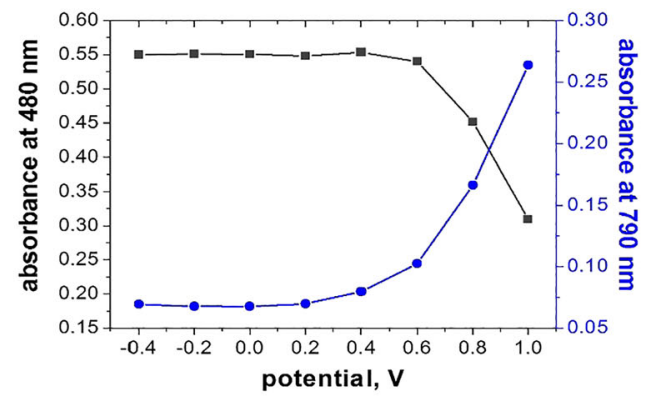

d 


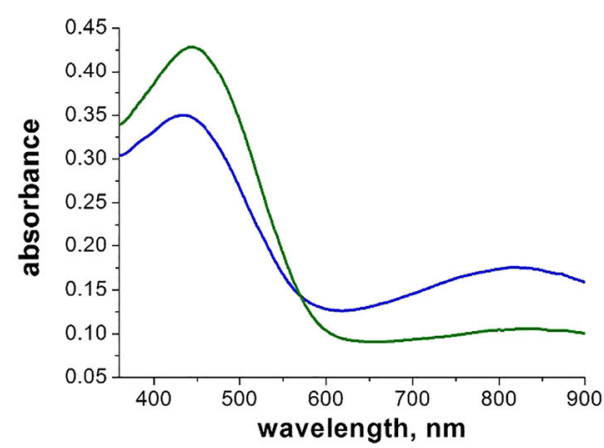

a

Fig. 7 Influence of sorbitol on optical spectra of poly-3-thenylboronic acid: the spectra in the presence (green) and in the absence (blue) of $500 \mathrm{mM}$ sorbitol at electrode potential $+0.8 \mathrm{~V}$ measured in aqueous buffer $10 \mathrm{mM}$ sodium phosphate, $140 \mathrm{mM} \mathrm{NaCl}, \mathrm{pH} 7.4$ (a) and

$35]$ or other sensors with electrochemically controlled affinity [36, 37]. The stability of the polymer films in an aqueous environment can be improved by using corresponding anchor layers, for example, by deposition of cationic polymers.

\section{Conclusion}

We have described preparation of a new chemosensitive material: thin and highly flexible films of poly-3-thienylboronic acid. The material can be prepared by electrochemical synthesis in situ; therefore, it is well compatible with methods of surface design and preparation of sensor arrays or materials libraries based on electrically addressed polymerization [38]. Electrochemical and spectral properties of this material are close to PTh, but the incorporated boronic acid moiety provides its chemical sensitivity to diol containing compounds. The ability to form stable films allows one to consider applications in support-free conditions, for example, for the formation of chemosensitive electromechanical actuators. Development of such systems and an analysis of its electrical conductivity and a preparation of conductometric chemosensors and electrochemical chemotransistors are the topics of our future work on this new material.

Acknowledgments The authors dedicate this work to the 65 th birthday of Professor Fritz Scholz. V. M. is grateful to him for interesting discussions of different topics of electrochemistry and the modern history of science. The authors would like to thank Mrs. S. Schicketanz for the excellent SEM images as well as Dr. K. Tonder and Dr. S. Nizamov for fruitful discussions and general assistance.

Funding Information Open Access funding provided by Projekt DEAL.

Open Access This article is licensed under a Creative Commons Attribution 4.0 International License, which permits use, sharing, adaptation, distribution and reproduction in any medium or format, as long as you give appropriate credit to the original author(s) and the source, provide a link to the Creative Commons licence, and indicate if changes were made. The images or other third party material in this article are included in the article's Creative Commons licence, unless indicated

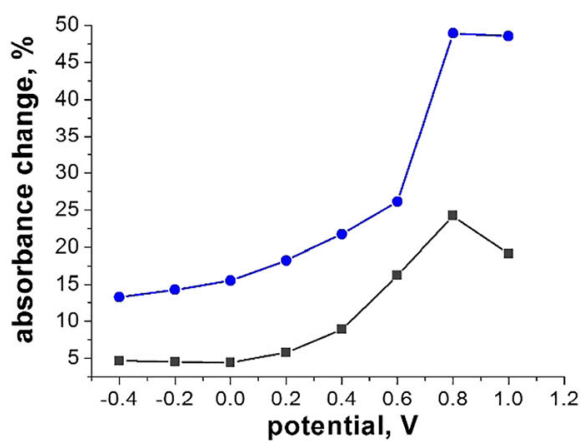

b

influence of the electrode potential and $\mathrm{pH}$ on the relative absorbance at $455 \mathrm{~nm}$ (b). The electrode potential is indicated vs. $\mathrm{Ag} / \mathrm{AgCl}(140 \mathrm{mM}$ $\mathrm{NaCl}$ ). $\mathrm{pH} 7.4$ (squares) or 8.0 (circles)

otherwise in a credit line to the material. If material is not included in the article's Creative Commons licence and your intended use is not permitted by statutory regulation or exceeds the permitted use, you will need to obtain permission directly from the copyright holder. To view a copy of this licence, visit http://creativecommons.org/licenses/by/4.0/.

\section{References}

1. Inzelt G (2008) Conducting polymers. A new era in electrochemistry. Springer, Germany

2. Inzelt G, Pineri M, Schultze JW, Vorotyntsev MA (2000) Electron and proton conducting polymers: recent development and prospects. Electrochim Acta 45(15-16):2403-2421

3. Heeger AJ (2010) Semiconducting polymers: the third generation. Chem Soc Rev 39(7):2354-2371

4. Pagés H, Topart P, Lemordant D (2001) Wide band electrochromic displays based on thin conducting polymer films. Electrochim Acta 46(13-14):2137-2143

5. Weidlich C, Mangold KM, Jüttner K (2001) Conducting polymers as ion-exchange for water purification. Electrochim Acta 47(5): 741-745

6. Paczosa-Bator B, Migdalski J (2006) Conducting polymers films as model biological membranes: electrochemical and ion exchange properties of poly(pyrrole) films dopped with asparagine and glutamine. Electrochim Acta 51(11):2173-2181

7. Holze R, Wu YP (2014) Intrinsically conducting polymers in electrochemical energy technology: trends and progress. Electrochim Acta 122:93-107

8. Niessen J, Rosenbaum M, Scholz F (2004) Fluorinated polyanilines as superior materials for electrocatalytic anodes in bacterial fuel cells. 6:571-575

9. Naveen HM, Gurudatt NG (2017) Applications of conducting polymer composites to electrochemical sensors: a review. Appl Mater Today 9:419-433

10. Zamani FG, Moulahoum H, Ak M (2019) Current trends in the development of conducting polymers-based biosensors. Trends Anal Chem 118:264-276

11. Otero TF, Martinez JG, Arias-Pardilla J (2012) Biomemetic electrochemistry from conducting polymers. a review: artificial muscles, smart membranes, smart drug delivery and computer/neuro interfaces. Electrochim Acta 84:112-128

12. Malinauskas A (1999) Electrocatalysis at conducting polymers. Synth Met 107(2):75-83 
13. Nielsen CB, Mcculloch I (2013) Recent advances in transistors performance of polythiophenes. Prog Polym Sci 38(12):2053-2069

14. Huynh TP, Sharma PS, Sosnowska M (2015) Functionalized polythiophenes: recognition materials for chemosensors and biosensors of superior sensitivity, selectivity and detectability. Prog Polym Sci 47:1-25

15. Gonçalves VC, Balogh DT (2012) Optical chemical sensors using polythiophene derivatives as active layer for detection of volatile organic compounds. Sensors Actuators B Chem 162(1):307-312

16. Kaloni TP, Giesbrecht PK, Schreckenbach G, Freund MS (2017) Polythiophene: from fundamental perspectives to applications. Chem Mater 19:10248-10283

17. Lange U, Mirsky VM (2011) Chemoresistors based on conducting polymers: a review on measurement techniques. Anal Chim Acta 687(2):105-113

18. Lange U, Mirsky VM (2012) Electroanalytical measurements without electrolytes: conducting polymers as probes for redox titration in non-conductive organic media. Anal Chim Acta 744:29-32

19. Lange U, Roznyatovskaya NV, Mirsky VM (2008) Conducting polymers in chemical sensors and arrays. Anal Chim Acta 614(1): $1-26$

20. Springsteen G, Wang B (2001) Alizarin Red S. as a general optical reporter for studying the binding of boronic acids with carbohydrates. Chem Commun 17:1608-1609

21. Yang X, Cheng Y, Jin S, Wang B (2010) In: VM Mirsky, AK Yatsimirsky (Eds.) Artificial receptors for chemical sensors. Wiley-VCH, Weinheim

22. Gray CW, Houston J, Houston TA (2002) Boronic acid receptors for $\alpha$-hydroxycarboxylates: high affinity of Shinkai's glucose receptor for tartrate. J Organomet Chem 67(15):5426-5428

23. Cambre JN, Sumerlin BS (2011) Biomedical applications of boronic acid polymers. Polymer 52(21):4631-4643

24. Yakuphanoglu F, Șenkal BF (2009) Electrical conductivity and optical properties of poly (3-thiophene boronic acid) organic semiconductor. Polym Eng Sci 49(4):722-726

25. Chen X, Zhang W, Zhu S, Wang S (2019) High-performance electrochromic device on polythiophene/poly(3-thiophene boronic acid) bilayer film. Org Electron 75:105373-105381

26. Cui L, Xu M, Zhu J, Ai S (2011) A novel hydrogen peroxide biosensor based on the specific binding of horseradish peroxidase with polymeric thiophene-3-boronic acid monolayer in hydrophilic room temperature ionic liquid. Synth Met 161(15-16):1686-1690
27. Şenel M, Dervisevic M, Çevikm E (2013) A novel amperometric glucose biosensor based on reconstitutuion of glucose oxidase on thiophene-3-boronic acid polymer layer. Curr Appl Phys 13(7): 1199-1204

28. Lange U, Mirsky VM (2011) Polythiophene films on gold electrodes: a comparison of bulk and contact resistances in aqueous and organic media. J Solid State Electrochem 15(11-12):23772382

29. Jin S, Cong S, Xue G, Xiong H, Mansdorf B (2002) Anisotropic polythiophene films with high conductivity and good mechanical properties via a new electrochemical synthesis. Adv Mater 14(20): 1492-1495

30. Nie G, Yang H, Wong S, Li X (2011) High-quality inherently organic conducting polymers electrosynthesised from fused-ring compounds in a new electrolytic system based on boron trifluoride diethyl etherate. Crit Rev Solid State Mater Sci 36(4):209-228

31. Schmidt-D'Aloisio K, Dong Y, Springborg M (2005) Properties of polythiophene and related conjugated polymers: a densityfunctional study. Phys Chem Chem Phys 14:142714-142722

32. Hao Q, Mirsky VM (2003) Morphology of electropolymerized poly (N-methylaniline) films. Microchim Acta 143(2-3):147-153

33. Shoji E, Freund MS (2002) Potentiometric saccharide detection based on the pKa changes of poly (aniline boronic acid). J Am Chem Soc 124(42):12486-12493

34. Pringsheim E, Terpetschnig E, Piletsky SA, Wolfbeis OS (1999) A polyaniline with near-infrared optical response to saccharides. Adv Mater 11(10):865-868

35. Lange U, Mirsky VM (2011) Integrated electrochemical transistor as a fast recoverable gas sensor. Anal Chim Acta 687(1):7-11

36. Efremenko Y, Mirsky VM (2017) Virtual sensor array consisting of a single sensor element with variable affinity: an application for analysis of fish freshness. Sensors Actuators B Chem 241:652-657

37. Efremenko Y, Mirsky VM (2016) Electrically controlled variation of receptor affinity. Anal Bioanal Chem 408(26):7283-7287

38. Potyrailo RA, Mirsky VM (2009) Combinatorial development of chemosensitive conductive polymers. In: Potyrailo RA, Mirsky VM (eds) Combinatorial Methods for Chemical and Biological Sensors. Springer, New-York

Publisher's note Springer Nature remains neutral with regard to jurisdictional claims in published maps and institutional affiliations. 